\title{
PENGARUH INOKULASI FUNGI MIKORIZA ARBUSKULA Glomus clorum, Glomus etunicatum DAN Gigaspora sp. TERHADAP PERTUMBUHAN SEMAI MAHONI DAN SERU
}

\author{
The Effect of Glomus clorum, Glomus etunicatum and Gigaspora sp. Inoculation \\ on the Growth of the Seedlings of Mahoni and Seru \\ Maliyana Ulfa, Efendi Agus Waluyo dan/and Edwin Martin \\ Balai Penelitian Kehutanan Palembang \\ Jl. Kol. H. Burlian Km. 6,5 Kotak Pos 179, Puntikayu, Palembang \\ Telp./Fax. (0711) 414864
}

Naskah masuk : 4 Februari 2008; Naskah diterima : 22 Januari 2009

\begin{abstract}
A research on the influence of Arbuscular Mycorrhizal Fungi (AMF) Glomus clorum, Glomus etunicatum and Gigaspora sp. inoculation to improve mahoni (Swietenia macrophylla) and seru (Schima walichii) seedlings growth during 4 months was conducted in nursery of PT. Bukit Asam, Tanjung Enim, South Sumatra. Research used four treatment namely G. clorum, G. etunicatum, Gigaspora sp. and control (without inoculation), arranged in Randomized Block Design with three replication. Growth parameters were height, diameter and shoot-root ratio. The result of research indicated that inoculation of $G$. clorum, G. etunicatum and Gigaspora sp. improved seru seedling growth, as shown by the improvement of their height and diameter. Mahoni, which were inoculated by G. clorum, G. etunicatum and Gigaspora sp., did not show good growth response.
\end{abstract}

Key word: Glomus clorum, Glomus etunicatum, Gigaspora sp., mahoni (Swietenia macrophylla), seru (Schima walichii)

\begin{abstract}
ABSTRAK
Penelitian pengaruh inokulasi Fungi Mikoriza Arbuskula (FMA) Glomus clorum, Glomus etunicatum dan Gigaspora sp. terhadap pertumbuhan semai mahoni dan seru telah dilakukan selama 4 bulan di persemaian PT Bukit Asam, Tanjung Enim, Sumatera Selatan. Penelitian menggunakan 4 perlakuan, yaitu inokulasi FMA G. clorum, G. etunicatum, Gigaspora sp. dan kontrol, menggunakan Rancangan Acak Blok dengan tiga ulangan. Parameter pertumbuhan yang diukur adalah tinggi, diameter dan berat kering total. Hasil penelitian menunjukkan bahwa Inokulasi G. clorum, G. etunicatum dan Gigaspora sp. mampu meningkatkan tinggi dan diameter seru di persemaian. Sedangkan mahoni tidak menunjukkan respon pertumbuhan yang baik akibat inokulasi G. clorum, G. etunicatum dan Gigaspora sp.
\end{abstract}

Kata kunci: Glomus clorum, Glomus etunicatum, Gigaspora sp., mahoni (Swietenia macrophylla), seru (Schima walichii)

\section{PENDAHULUAN}

\section{A. Latar Belakang}

Pemanfaatan hutan yang terus menerus berdampak negatif bagi kelestarian hutan. Pengaruh secara langsung bagi kelestarian hutan adalah berubahnya kondisi fisik dan kimia dari hutan. Dampak dari pemanfaatan hutan yang berlebihan akan mengakibatkan degradasi lahan dan adanya lahan-lahan kritis yang sulit ditanami lagi.

Penurunan secara kuantitas juga diikuti dengan degradasi kualitas lahan, baik akibat praktek konversi lahan yang mengabaikan ekologi maupun karena karakteristik tanah yang khas. Lahan kering 
dengan karakteristik tanah yang khas, dijumpai tanah dengan faktor pembatas berupa kekurangan hara dan kekurangan air. Kemiskinan bahan organik akan memperburuk struktur tanah, terutama pada tanah yang bertekstur kasar sehubungan dengan taraf pelapukan yang rendah (Notohadinagoro, 1997). Selain menghadapi kendala karakter lahan yang tidak ideal, perubahan lingkungan berpengaruh pula pada kehidupan makhluk hidup yang lain. Populasi hama menjadi tidak terkendali dan tanaman menjadi rentan dengan serangan penyakit.

Mahoni dan seru (Schima sp.) digunakan sebagai tanaman revegetasi lahan kritis di DAS Citanduy (Dwiprabowo \& Wulan, 2003). Upaya rehabilitasi lahan pada umumnya dihadapkan pada kendala penyiapan bibit yang masih buruk. Menurut Turjaman et al. (2002), upaya tersebut sering dihadapkan pada kendala penyiapan bibit yang masih di bawah standar, baik secara kualitas dan kuantitas. Dari segi kualitas, masih banyak bibit tanaman hutan yang mengalami kematian setelah dipindahkan ke lapangan.

Fungi Mikoriza Arbuskula (FMA) sebagai salah satu jamur pembentuk mikoriza, merupakan salah satu upaya pembekalan bibit tanaman hutan untuk merehabilitasi lahan marginal. Pada tahap persemaian, akan dapat meningkatkan laju pertumbuhan tanaman. Penanaman di lahan marginal, tanaman rehabilitasi bermikoriza akan lebih tahan terhadap kekeringan, lebih mudah menyerap unsur hara, tahan terhadap serangan patogen akar dan diperolehnya hormon dan zat pengatur tumbuh. Manfaat inokulasi mikoriza jenis endomikoriza dilaporkan oleh Setiadi (1996), bahwa pada tanaman bonu (Trichospermum burreti), sengon (Paraserianthes falcataria) dan mangium (Acacia mangium), ketiganya mampu beradaptasi dan tumbuh pada lahan bekas pertambangan nikel. Pertumbuhannya meningkat 2 - 3 kali lipat, sehingga dapat disetarakan dengan pemberian pupuk urea $130 \mathrm{~kg} / \mathrm{ha}$, TSP 180 $\mathrm{kg} / \mathrm{ha}$ dan $\mathrm{KCl} 100 \mathrm{~kg} / \mathrm{ha}$. Santoso et al. (2003) menyebutkan bahwa mahoni juga berasosiasi dengan Fungi Mikoriza Arbuskula.

Berdasarkan hal-hal tersebut, maka perlu dilakukan penelitian dalam upaya penyediaan bibit mahoni dan seru sebagai tanaman revegetasi dengan mengaplikasikan 3 jenis FMA (G. etunicatum, $G$. clorum dan Gigaspora sp.) pada tahap persemaian untuk menambah keberhasilan rehabilitasi di lahan marginal.

\section{B. Tujuan}

Tujuan penelitian ini adalah untuk mengetahui pengaruh inokulasi beberapa Cendawan Mikoriza Arbuskular terhadap pertumbuhan semai mahoni (Swietenia macrophylla) dan seru (Schima walichii) di persemaian.

\section{BAHAN DAN METODE}

\section{A. Waktu dan Lokasi}

Penelitian ini dilakukan di persemaian PT Batubara Bukit Asam, Tanjung Enim, Sumatera Selatan, pada Agustus sampai dengan Nopember tahun 2004.

\section{B. Bahan dan Alat}

Bahan-bahan yang digunakan meliputi : (1) Inokulum 3 isolat FMA hasil produksi massal Laboratorium Mikrobiologi Hutan, Puslitbang Hutan dan Konservasi Alam, Bogor dalam bentuk potongan akar dalam zeolith; (2) Benih seru dan mahoni; (3) Media tanam (pasir sungai dan topsoil ultisol); (4) Polybag; (5) Larutan $\mathrm{H}_{2} \mathrm{O}_{2} 5 \%$.

Peralatan yang dipakai selama masa penelitian yaitu autoclave, neraca analitis, sprayer dan gembor, shading net intensitas $65 \%$, bak kecambah, mistar ukur, jangka sorong dan seperangkat alat pertukangan.

\section{Metode Penelitian}

\section{Pembuatan media kecambah dan semai}

Media dipersiapkan untuk mengecambahkan benih-benih koleksi dan sebagai tempat tumbuh semai sapihan. Media kecambah berupa pasir sungai dalam wadah bak kecambah. Media semai yaitu 
campuran top soil dengan pasir, dengan perbandingan volume $1: 1$. Media semai dikemas dalam polybag berukuran tinggi $14 \mathrm{~cm}$, diameter $8 \mathrm{~cm}$. Media kecambah dan semai sebelumnya disterilkan dalam otoklaf pada tekanan $1 \mathrm{~atm}$, suhu $121^{\circ} \mathrm{C}$ selama 30 menit.

\section{Pengecambahan benih}

Benih yang akan dikecambahkan terlebih dahulu diseleksi dan permukaannya disterilkan dengan cara direndam dalam larutan $\mathrm{H}_{2} \mathrm{O}_{2}(5 \%)$ selama 10 menit, kemudian benih ditaburkan secara merata pada media kecambah yang telah disiapkan.

\section{Penanaman kecambah dan inokulasi mikoriza}

Penyapihan semai dilakukan setelah kecambah berumur 30 hari. Sebanyak 360 semai masingmasing jenis tanaman yang penampakannya seragam dipindahkan ke dalam polybag yang berisi media steril, sesuai dengan perlakuan. Inokulasi mikoriza dilakukan tiga hari setelah penyapihan setelah semai melewati masa stress dengan dosis 5 gram/tanaman inokulum endomikoriza.

\section{Rancangan penelitian}

Penelitian ini menggunakan Percobaan Faktorial dengan Rancangan Acak Kelompok (RAK) dengan perlakuan berupa pemberian 3 jenis inokulum endomikoriza (M), yaitu G. etunicatum, G. clorum, Gigaspora sp. dan kontrol. Ulangan dilakukan sebanyak 3 kali pada setiap perlakuan, sehingga menghasilkan $4 \times 3=12$ unit penelitian per jenis tanaman. Dalam setiap unit penelitian terdapat 30 individu perlakuan. Apabila dari hasil analisa keragaman menunjukkan perbedaan yang nyata, maka dilanjutkan dengan uji beda nyata metode Duncan.

\section{Parameter yang Diamati}

Parameter yang diamati dan diukur untuk penelitian skala persemaian adalah riap tinggi $(\mathrm{cm})$, diameter $(\mathrm{mm})$ dan berat kering total (gram). Untuk mengetahui adanya infeksi pada akar karena adanya inokulasi FMA, maka dilakukan pengamatan secara mikroskopis pada sample akar tanaman.

\section{HASIL DAN PEMBAHASAN}

Pengamatan pengaruh inokulasi FMA, yaitu Glomus clorum, Glomus etunicatum dan Gigaspora sp. terhadap pertumbuhan semai mahoni (Swietenia macrophylla) dan seru (Schima walichii) berdasarkan parameter tinggi, diameter dan berat kering total. Analisis sidik ragam menunjukkan bahwa inokulasi FMA tidak berpengaruh nyata terhadap parameter parameter pertambahan tinggi, diameter dan berat kering total mahoni. Sedangkan pada tanaman seru, inokulasi oleh ketiga FMA berpengaruh sangat nyata pada pertambahan tinggi dan diameter (Tabel 1). Pengaruh FMA G. clorum, G. etunicatum dan Gigaspora sp. terhadap riap tinggi, diameter dan berat kering total mahoni dan seru disajikan pada Tabel 2.

Tabel(Table) 1. Analisis sidik ragam pengaruh FMA G. clorum, G. etunicatum dan Gigaspora sp. terhadap pertumbuhan mahoni dan seru umur 4 bulan di persemaian (Analysis of variance of the effect of $A M F \mathrm{G}$. clorum, G. etunicatum and Gigaspora sp. on the growth of mahoni and seru with the age of 4 months in the nursery)

\begin{tabular}{|l|l|c|c|}
\hline $\begin{array}{c}\text { Jenis Tanaman } \\
\text { (Species) }\end{array}$ & \multicolumn{1}{|c|}{$\begin{array}{c}\text { Parameter Pertumbuhan } \\
\text { (Growth Parameter })\end{array}$} & $\begin{array}{c}\text { Kuadrat Tengah } \\
(\text { Med Square })\end{array}$ & $\begin{array}{c}\text { F hitung } \\
(\text { F calc. })\end{array}$ \\
\hline Mahoni & Pertambahan tinggi & 1,11 & 1,23 \\
& Pertambahan diameter & 0,08 & 1,24 \\
& Berat kering total & 1,68 & 2,11 \\
\hline Seru & Pertambahan tinggi & 10,51 & $4,90^{* *}$ \\
& Pertambahan diameter & 0,21 & $17,4^{* *}$ \\
& Berat kering total & 1,37 & 2,52 \\
\hline
\end{tabular}

Keterangan (Notes) : Berpengaruh sangat nyata pada taraf 1\% (Highly significantly difference at 1\% level) 
Tabel(Table) 2. Pengaruh FMA G. clorum, G. etunicatum dan Gigaspora sp. terhadap riap tinggi, diameter dan berat kering total mahoni dan seru umur 4 bulan di persemaian (The effect of FMA of G. clorum, G. etunicatum and Gigaspora sp. on the increment of height diameter and total any weight of 4 months old mahoni and seru)

\begin{tabular}{|l|l|c|c|c|}
\hline \multirow{3}{*}{$\begin{array}{c}\text { Jenis Tanaman } \\
\text { (Species) }\end{array}$} & $\begin{array}{c}\text { Perlakuan } \\
\text { (Treatment) }\end{array}$ & $\begin{array}{c}\text { Pertambahan } \\
\text { Tinggi (Height } \\
\text { Increment })(\mathrm{cm})\end{array}$ & $\begin{array}{c}\text { Pertambahan Diameter } \\
\text { (Diameter Increment) } \\
(\mathrm{mm})\end{array}$ & $\begin{array}{c}\text { Berat Kering } \\
\text { Total (Total Dry } \\
\text { Weight) }(\mathrm{gram})\end{array}$ \\
\hline Mahoni & M.C & 7,1 & 2,5 & 6,17 \\
& M.E & 7,1 & 2,8 & 4,41 \\
& M.G & 7,2 & 2,5 & 5,87 \\
& Kontrol & 8,5 & 2,6 & 6,56 \\
\hline Seru & M.C & $8,3 \mathrm{a}$ & $1,4 \mathrm{a}$ & 1,91 \\
& M.E & $8,0 \mathrm{a}$ & $1,3 \mathrm{a}$ & 2,29 \\
& M.G & $6,7 \mathrm{a}$ & $1,3 \mathrm{a}$ & 2,23 \\
& Kontrol & $3,3 \mathrm{~b}$ & $0,7 \mathrm{~b}$ & 0,99 \\
\hline
\end{tabular}

Keterangan (Notes) : Angka diikuti huruf yang sama dalam satu kolom tidak berbeda nyata pada taraf $\mathrm{P}<0,05$ $\begin{array}{ll}\text { M.C } & =\text { Perlakuan inokulasi G. clorum (Inoculated by G. clorum) } \\ \text { M.E } & =\text { Perlakuan inokulasi G. etunicatum (Inoculated by G. etunicatum) } \\ \text { M.G } & \text { Perlakuan inokulasi Gigaspora } \text { sp. (Inoculated by Gigaspora } s p .)\end{array}$ Kontrol $($ Control $)=$ Tidak diinokulasi

Perlakuan tiga FMA pada mahoni tidak menunjukkan pertambahan tinggi, diameter dan berat kering total dibandingkan mahoni yang tidak diinokulasi (Gambar 1). Pada seru, perlakuan tiga FMA memberikan pengaruh pertambahan tinggi dan diameter dibandingkan seru yang tidak diinokulasi. Meskipun perlakuan inokulasi menghasilkan berat kering total yang lebih baik dibandingkan yang tidak diinokulasi, namun berdasarkan analisis sidik ragam inokulasi FMA tidak menunjukkan beda nyata dibandingkan yang tidak diinokulasi (Gambar 2).
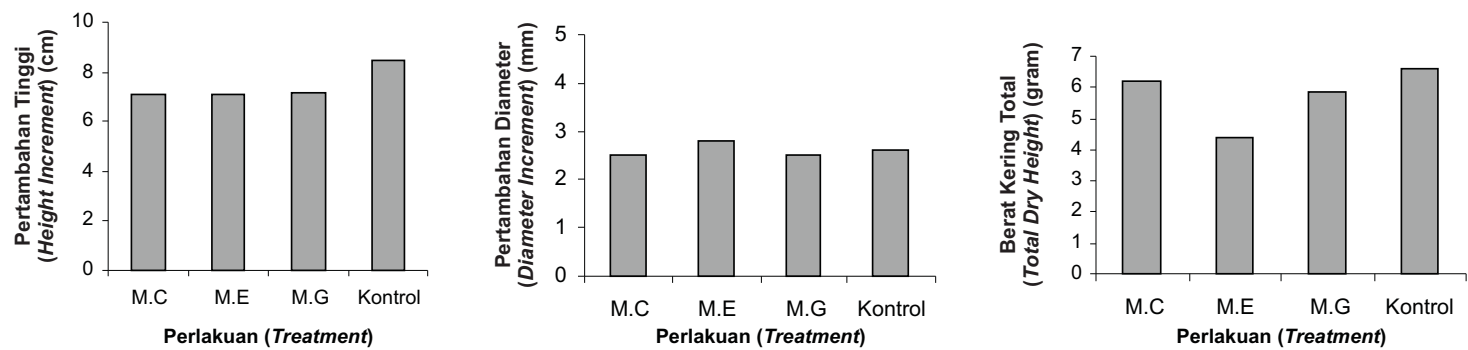

Gambar (Figure) 1. Grafik respon pertumbuhan mahoni umur 4 bulan di persemaian dengan berbagai perlakuan (The chart on the response of mahoni's growth in the nursery with various treatments)
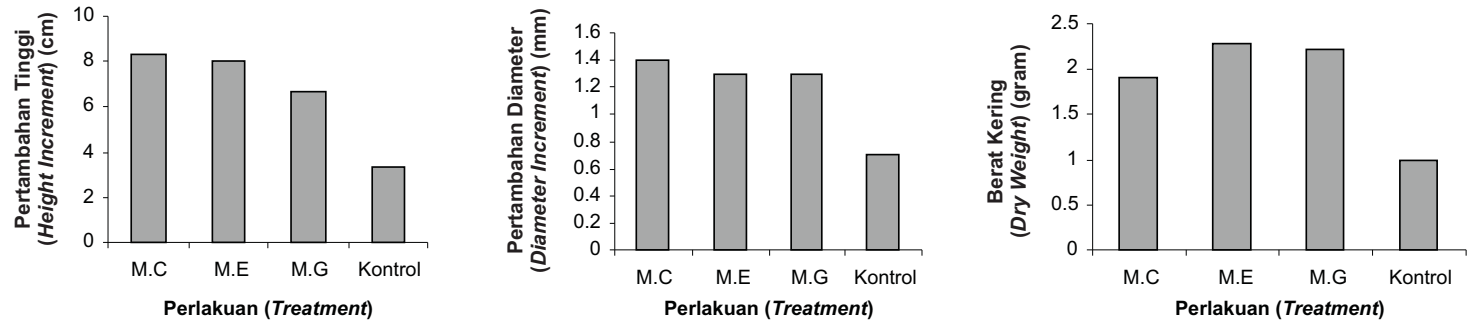

Gambar(Figure) 2. Grafik respon pertumbuhan seru umur 4 bulan di persemaian dengan berbagai perlakuan (The chart on the response of 4 month old seru's growth in the nursery with various treatments) 
Peningkatan riap tertinggi terdapat pada tanaman seru yang diinokulasi G. clorum adalah sebesar $82,18 \%$, diikuti seru yang diinokulasi Gigaspora sp. (81,63\%), kemudian seru yang diinokulasi $G$. etunicatum $(79,76 \%)$. Pada tanaman mahoni, justru riap tertinggi terdapat pada mahoni yang tidak diinokulasi (31,48\%), diikuti mahoni yang diinokulasi G. clorum $(27,84 \%)$, kemudian mahoni yang diinokulasi G. etunicatum (27,80\%) dan Gigaspora sp. (27,41\%). Hal ini menunjukkan bahwa semai seru responsif terhadap perlakuan inokulasi ketiga FMA, terutama G. clorum, disusul G. etunicatum kemudian Gigaspora sp., sedangkan mahoni tidak menunjukkan respon pertumbuhan yang baik dengan perlakuan inokulasi tiga jenis FMA.

Perbedaan respon masing-masing jenis tanaman terhadap inokulasi ketiga FMA menunjukkan tingkat efektivitas FMA dalam merangsang pertumbuhan masing-masing tanaman. Hal ini pernah dinyatakan oleh Mosse (1973), bahwa FMA tidak mempunyai inang yang spesifik, namun jenis tertentu dapat lebih merangsang pertumbuhan jenis tanaman tertentu atau dengan kata lain tingkat efektivitas satu jenis jamur pembentuk FMA berbeda-beda terhadap jenis tanaman. Bahkan jenis tanaman hutan tertentu tidak memberikan respon pertumbuhan yang positif terhadap pemberian FMA(Setiadi, 1996).

Tanaman yang memiliki berat kering total lebih besar berarti produktivitas dan perkembangan sel-sel jaringannya tinggi dan cepat. Kecenderungan meningkatnya berat kering tanaman berkaitan dengan metabolisme tanaman atau karena adanya kondisi pertumbuhan yang lebih baik bagi berlangsungnya aktivitas metabolisme tanaman (Widyani et al., 2003). Pada mahoni, inokulasi FMA tidak menghasilkan berat kering total yang lebih baik dibandingkan kontrol. Hal ini juga dijumpai pada penelitian inokulasi FMA dan pupuk fosfat yang dilakukan oleh Sari (1999), yang menunjukkan bahwa berat kering total lebih baik pada perlakuan tanpa FMA dan pupuk fosfat. Berat kering total lebih bagus bila berinteraksi dengan pupuk fosfat pada dosis yang lebih inggi $(180 \mathrm{~kg} / \mathrm{ha})$. Sedangkan pemberian inokulum osakagas lebih baik jika berinteraksi dengan pupuk fosfat pada dosis $45 \mathrm{~kg} / \mathrm{ha}$ dan $180 \mathrm{~kg} / \mathrm{ha}$. Pada seru yang diinokulasi FMA, selain mengalami peningkatan riap tinggi dan diameter, juga mengalami peningkatan berat kering total dibandingkan kontrol. Hal ini akan mendukung bibit seru yang diinokulasi FMA lebih bisa bertahan apabila ditanam di lapangan. Ahmad (1992) menyebutkan penyebab secara fisik meningkatnya aktivitas pengambilan unsur hara pada akar bermikoriza, karena (a) bertambahnya luas permukaan akar yang berfungsi sebagai penyerap unsur hara; dan (b) bertambahnya periode akar yang berfungsi sebagai penyerap unsur hara. Sedangkan secara kimia, asosiasi mikoriza dapat menyebabkan tanaman mampu memanfaatkan sumber-sumber fosfor yang tidak tersedia (Suciatmih, 1996)

Tabel(Table) 3. Rata-rata berat kering total dan rasio pucuk akar semai mahoni dan seru umur 4 bulan di persemaian (Average total dry weight and the ratio of the root's edge of mahoni and seru seedlings of 4 months age on nursery)

\begin{tabular}{|c|c|c|c|c|}
\hline \multirow{2}{*}{$\begin{array}{c}\text { Jenis Tanaman } \\
\text { (Species) }\end{array}$} & \multirow{2}{*}{$\begin{array}{l}\text { Perlakuan } \\
\text { (Treatment) }\end{array}$} & \multicolumn{2}{|c|}{ Berat kering (Dry weight) } & \multirow{2}{*}{$\begin{array}{l}\text { Rasio pucuk akar } \\
\text { (Root edge ratio) }\end{array}$} \\
\hline & & Pucuk (Edge) & $\operatorname{Akar}($ Root $)$ & \\
\hline Mahoni & $\begin{array}{l}\text { M.C } \\
\text { M.E } \\
\text { M.G } \\
\text { Kontrol }\end{array}$ & $\begin{array}{l}4,89 \\
4,51 \\
2,92 \\
5,03\end{array}$ & $\begin{array}{l}1,28 \\
1,36 \\
1,49 \\
1,53\end{array}$ & $\begin{array}{l}3,82 \\
3,32 \\
1,96 \\
3,29\end{array}$ \\
\hline Seru & $\begin{array}{l}\text { M.C } \\
\text { M.E } \\
\text { M.G } \\
\text { Kontrol }\end{array}$ & $\begin{array}{l}1,43 \\
1,77 \\
1,90 \\
0,78\end{array}$ & $\begin{array}{l}0,48 \\
0,46 \\
0,39 \\
0,20\end{array}$ & $\begin{array}{l}2,98 \\
3,85 \\
4,87 \\
3,90\end{array}$ \\
\hline
\end{tabular}

Pertumbuhan akar yang baik sangat diperlukan untuk mendorong penyerapan hara dan air yang lebih tinggi dibandingkan dengan semai yang mempunyai akar kurang lebat. Selain itu semai yang mempunyai jumlah akar lebih banyak dan kompak dapat membantu adaptasi semai saat ditanam di lapangan. Semai yang memiliki berat kering total besar berarti mempunyai produktivitas tinggi dan perkembangan jaringan cepat. Menurut Gonzal et al. (1995), pertumbuhan yang cepat dari semai yang diinokulasi FMA mempunyai peningkatan daerah permukaan akar yang tinggi sehingga memungkinkan tanaman menyerap air dan nutrisi secara efisien. Inokulasi ketiga FMA pada mahoni tidak memberikan 
berat kering akar yang lebih besar daripada kontrol, sedangkan pada seru dihasilkan berat kering akar yang lebih besar daripada kontrol (Tabel 3). Nilai tersebut mengindikasikan bahwa berat kering akar seru mendukung efektifivas inokulasi. Pertumbuhan yang cepat dari semai yang diinokulasi dengan FMA dapat diduga dari peningkatan daerah permukaan akar yang memungkinkan tanaman menyerap air dan hara secara efisien. Selain itu berdasarkan berat kering pucuk pada mahoni yang diinokulasi, perkembangan bagian pucuk lebih kecil daripada yang tidak diinokulasi, sedangkan pada seru dihasilkan berat kering pucuk yang lebih besar daripada kontrol, yang mengindikasikan bahwa pengangkutan unsur hara di seru lebih baik dengan adanya inokulasi FMA. Inokulasi Gigaspora sp. pada seru mampu meningkatkan rasio pucuk akar terbaik sebesar 24,87\%. Sedangkan pada mahoni, inokulasi G. clorum mampu meningkatkan rasio pucuk akar terbaik sebesar 16,11\%. Menurut Yuniawati (1998), nilai Rasio Pucuk Akar yang tinggi menunjukkan kemampuan perkembangan bagian pucuk lebih tinggi daripada perkembangan akar, yang menggambarkan bahwa unsur hara yang tersedia dapat diangkut dengan baik oleh akar dan hasilnya digunakan secara optimal untuk memacu pertumbuhan bagian pucuk tanaman. Unsur hara yang secara dominan dibantu penyerapannya oleh mikoriza adalah fosfor (Fakuara, 1988; Smith and Smith, 1990 dan Marschner, 1992). Tidak efektifnya inokulasi ketiga FMA pada mahoni diduga disebabkan oleh perakaran mahoni yang kurang lebat, sehingga tidak mendukung terbentuknya asosiasi yang baik antara FMA dengan akar. Selain itu, meskipun secara mikroskopis ketiga FMA mampu menginfeksi akar mahoni, namun hal tersebut tidak menjamin adanya asosiasi akar dan FMA yang diharapkan mampu meningkatkan pertumbuhan tanaman (Gambar 3). Sedangkan pada seru, keberadaan FMA pada akar mampu meningkatkan pertumbuhan tanaman.

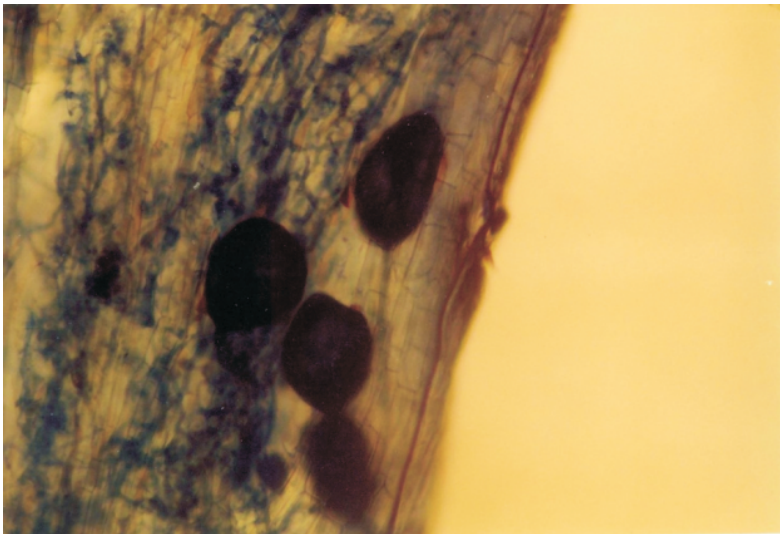

a

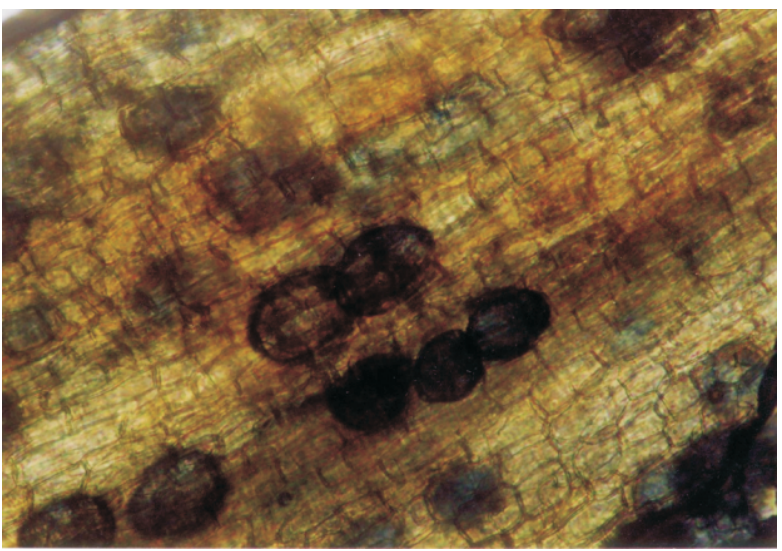

$\mathrm{c}$

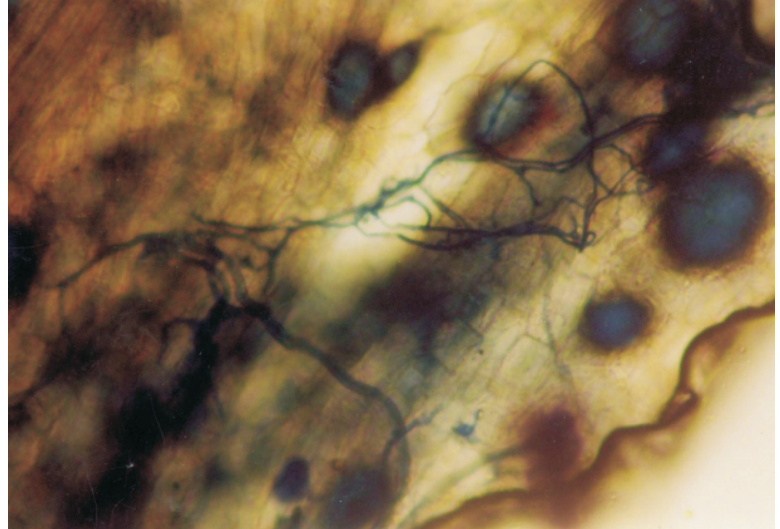

$\mathrm{b}$

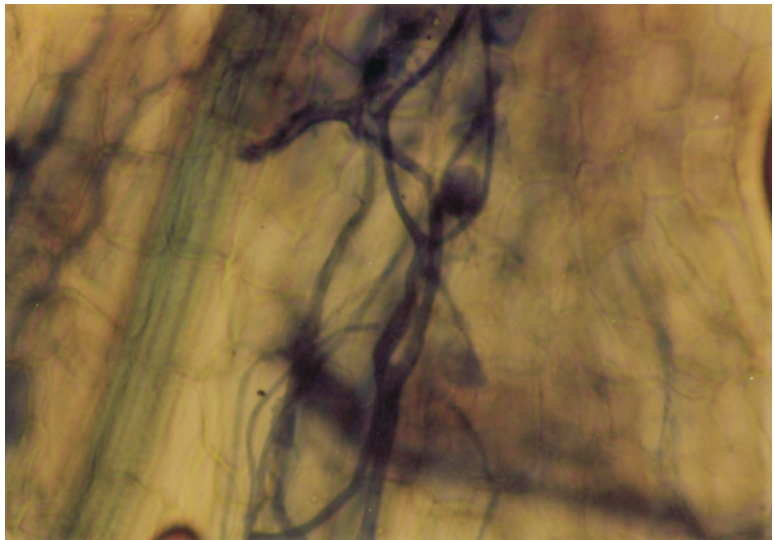

d

Gambar(Figure)3. Keberadaan hifa and vesikel pada korteks akar semai mahoni yang diinokulasi Gigaspora sp. (a), G. clorum (b), G. etunicatum (c) dan kontrol (d) (Hypha and vesicles in the cortex of mahoni s seedling 's root which is inoculated by Gigaspora $s p$. (a), G. clorum (b), G. etunicatum (c) and control (d)) 


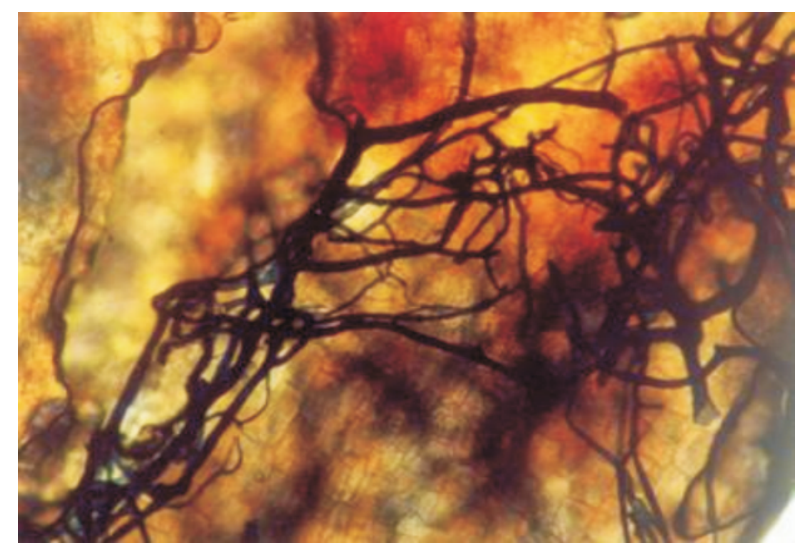

a

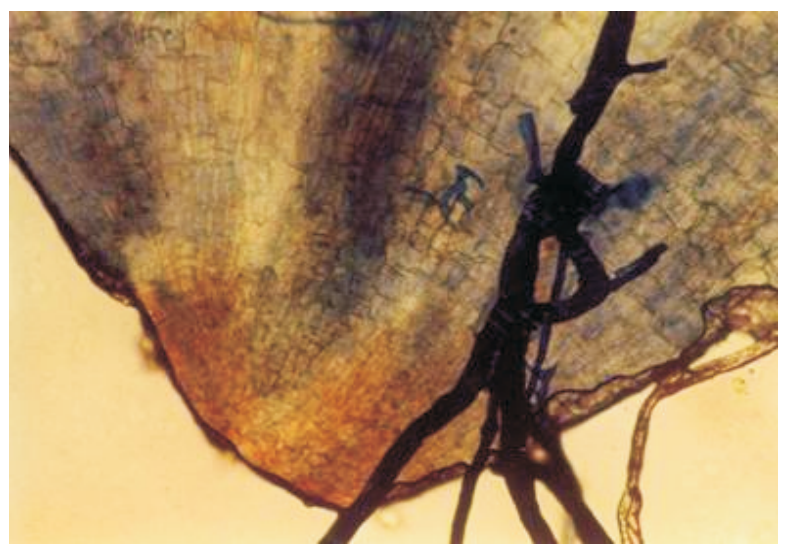

$\mathrm{b}$

Gambar(Figure) 4. Keberadaan hifa and vesikel pada korteks akar semai seru yang diinokulasi $G$. etunicatum (a) dan kontrol (b) (Hypha and vesicle in the cortex of seru seedling 's root inoculated by G. etunicatum (a) and control (b))

\section{KESIMPULAN DAN SARAN}

\section{A. Kesimpulan}

1. Perlakuan inokulasi Glomus clorum, Glomus etunicatum dan Gigaspora sp. mampu meningkatkan pertumbuhan seru di persemaian.

2. Perlakuan inokulasi infeksi G. clorum, G. etunicatum dan Gigaspora sp. pada mahoni tidak menunjukkan efektivitas untuk meningkatkan pertumbuhan meskipun ditemukan adanya infeksi ketiga FMA pada perakaran.

\section{B. Saran}

Untuk melihat peran FMA yang lebih nyata, tanaman hasil penelitian tersebut disarankan dapat ditanam pada kondisi lahan kritis, sehingga dapat diamati ketahanannya terhadap kekeringan, patogen akar, serta dalam penyerapan unsur hara.

\section{DAFTAR PUSTAKA}

Ahmad. 1992. Beberapa Aspek perihal Ektomikoriza dan Fiksasi Nitrogen Secara Biologis. Fakultas Kehutanan IPB. Bogor.

Dwiprabowo, H. dan Wulan, Y. C. 2003. A Description of the Citanduy Watershed, West Java and Preliminary Analysis of Carbon-Sequestration Potential by Smallholders. Working paper CC09, ACIAR project ASEM 1999/093. Center for Socio-economic Research on Forestry. Bogor. Indonesia. http ://www.une.edu.au/carbon/CC09. Diakses pada tanggal 15 Desember 2006.

Fakuara, M.Y. 1988. Mikoriza, Teori dan Kegunaan dalam Praktek. Pusat Antar Universitas Bioteknologi IPB. Bogor.

Gonzal, D. G., L. U. de la Cruz and L. R. Gonzal. 1995 Growth performance of Gmelina arborea in volcanic ash and acid soil after innoculation with VA mycorrhiza in International Symposium on Recent Advances in Tropical Tree Seed Technology and Planting Stock Production, 12-14 June 1995. p. 213-217. ASEAN Forest Tree Seed Centre Project. Muak-Lek, Saraburi, Thailand.

Marschner. 1992. Mycorrhiza. http : mycorrhiza.ag.utk.edu/latest/1992/92_weber1.htm. Diakses pada tanggal 12 September 2008. 
Mosse. 1973. Mycorrhiza and Soil Phosphorus Levels. http : mining.state.co.us/.../ MycorrhizaAndSoilPhosporusLevel.pdf. Dikses pada tanggal 12 September 2008.

Notohadinagoro, T. 1997. Bercari Amanat Pengelolaan Berkelanjutan sebagai Konsep Pengembangan Wilayah Lahan Kering. Makalah Seminar Nasional dan Peatihan Pengelolaan Lahan Kering FOKUSHIMITI di Jember. Universitas Jember. Jember.

Santoso, E., R.S.B. Irianto dan M. Turjaman. 2003. Teknologi Mikoriza. Badan Penelitian dan Pengembangan Kehutanan Departemen Kehutanan. Jakarta.

Sari, N. M. 1999. Pengaruh Inokulasi Cendawan Mikoriza Arbuskula dan Pemberian Pupuk Fosfat untuk Meningkatkan Pertumbuhan Semai Swietenia macrophylla King. pada Tanah Latosol dan Podsolik Merah Kuning. Jurusan Manajemen Hutan, Fakultas Kehutanan, Institut Pertanian Bogor. Skripsi. Tidak dipublikasikan.

Setiadi, Y. 1996. The practical application of arbuscular mycorrhizal fungi for enhancing tree establishment in degraded nickel mine sites at PT. INCO, Soroako. Paper presented on IUFRO International Symposium on Accelerating Natural Succession of Degraded tropical Lands 11- 13 June 1996. Washington.

Smith, S. E. and Smith, F. A. 1990. Structure and function of the interfaces in biotrophic symbioses as they relate to nutrient transport. http : www.interscience.wiley.com/journal. Diakses pada tanggal 12 September 2008.

Suciatmih. 1996. Bagaimana Jamur Mikoriza Vesikular-Arbuskular Meningkatkan Ketersediaan dan Pengambilan Fosfor? Warta Biotek X No. 4, Desember 1996. Hal 4-7.

Turjaman, M., R.S.B. Irianto, I.R. Sitepu, E. Widyati dan E. Santoso. 2002. Aplikasi produk ektomikoriza dalam kapsul alginat untuk peningkatan mutu bibit tanaman hutan sebagai pemacu program rehabilitasi dan konservasi lahan di Indonesia. Prosiding Diskusi Hasil-hasil Litbang. Rehabilitasi dan Konservasi Sumberdaya Hutan. Bogor, 23 Desember 2002. Pusat Penelitian dan Pengembangan Hutan dan Konservasi Alam. Bogor.

Widyani N. , Y. Setiadi, D.J. Sudrajat. 2003. Pengaruh Inokulasi Mikoriza Arbuskular dan Pemberian Pupuk Fosfat terhadap Pertumbuhan Semai Gmelina (Gmelina arborea Roxb.). Buletin Teknologi Perbenihan Vol. 10 No. $1: 35$ - 48.

Yuniawati, Y. 1998. Uji Infektivitas dan Efektivitas Cendawan Glomus sp. dan Gigaspora sp. terhadap Pertumbuhan Stek Batang Sungkai (P. canescens Jack.) pada Berbagai Dosis Pupuk Batuan Fosfat. Jurusan Manajemen Hutan, Fakultas Kehutanan, Institut Pertanian Bogor. Skripsi. Tidak dipublikasikan. 